\title{
Analisa Dan Pengembangan Sistem Informasi Distribusi Dan Penjualan Cv Jogja Konveksi
}

\author{
Triyolla Ivandina ${ }^{1}$, Yuhandri, Aggy Pramana Gusman ${ }^{3}$ \\ ${ }^{1}$ Universitas Putra Indonesia "YPTK" Padang, Indonesia \\ ${ }^{2}$ Universitas Putra Indonesia "YPTK" Padang, Indonesia \\ ${ }^{3}$ Universitas Putra Indonesia "YPTK" Padang, Indonesia
}

Email: Triyolaivadina@gmail.com, Yuhandri.yunus@gmail.ac.id, Apgusman@gmail.com

\begin{abstract}
The system applied by CV Jogja Convection which is one of the distributors in the city of Padang. In the data processing information system that supports sales which includes goods data, customer or customer data, and others. The design of this system is one of the choices to help the distribution of goods such as sales at CV Jogja Convection. The information system created is based on a website and has a function as a medium for the distribution of goods CV Jogja Convection. This web-based information system can speed up accurate data entry and fast search processes in sales information systems in particular.
\end{abstract}

Keywords: Online Sales, Distribution, Information Systems, Web

\begin{abstract}
Abstrak
Sistem yang diterapkan CV Jogja Konveksi yang merupakan salah satu distributor yang ada di Kota Padang. Pada sistem informasi pengolahan data menunjang penjualan yang meliputi data barang, data konsumen atau pelanggan, dan lain-lain. Perancangan sistem ini merupakan salah satu pilihan untuk membantu operasional pendistribusian barang seperti penjualan di CV Jogja Konveksi. Sistem informasi yang dibuat berbasis website dan memiliki fungsi sebagai media pendistribusian barang CV Jogja Konveksi.Sistem informasi berbasis web ini dapat mempercepat entri data yang akurat serta proses pencarian yang cepat didalam sistem informasi penjualan pada khususnya.
\end{abstract}

Kata kunci: Penjualan Online, Pendistribusian, Sistem Informasi, Web.

\section{Pendahuluan}

Sistem informasi adalah cara-cara yang diorganisasi untuk mengumpulkan, memasukkan, dan mengolah serta menyimpan data, dan cara-cara yang diorganisasi untuk menyimpan, mengelola, mengendalikan, dan melaporkan informasi sedemikian rupa sehingga sebuah organisasi dapat mencapai tujuan yang telah ditetapkan. Pengertian menurut Krismaji (2015:15) Dengan kondisi demikian tentu perlu dikembangkan suatu sistem komputerisasi untuk mengolah data mengenai penjualan dan distribusi serta mampu menangani dan menciptakan informasi data pada CV Jogja Konveksi tersebut. Dengan harapan akan dapat memperbaiki kekurangan yang terjadi selama ini.Untuk memecahkan permasalahan di atas penulis ingin membangun sebuah sistem informasi pendistribusian dan penjualanpada cv.jogja konveksi.

CV Jogja Konveksi merupakan toko yang bergerak dibidang penjualan baju seragam yang banyak dibutuhkan oleh semua pihak baik itu mahasiswa,karyawan,organisasi dll. Namun sebagai toko yang cukup berpotensi CV Jogja Konveksi belum memiliki sistem penjualan secara komputerisasi sehingga informasi yang diperoleh kurang akurat. Terkadang terjadi kesalahan pengiriman atau pencatatan yang tidak tepat serta seringnya kesalahan dalam pembuatan laporan dan keterlambatan dalam pembuatan faktur dan laporan penjualan.

UML (Unified Modelling Language) adalah salah satu standar bahasa yang banyak digunakan didunia industri untuk mendefinisikan requirement, membuat analisis dan desain, serta menggambarkan arsitektur dalam pemrograman berorientasikan objek Menurut Rosa Dan Shalahuddin (2015:133).

Internet memungkinkan satu individu untuk terhubung dengan satu atau lebih individu lainnya baik untuk berkomunikasi, menerima serta menyebarkan informasi. (Pibriana,D. \& Ricoida, D. I. 2017), Dengan adanya internet seseorang bisa mengakses website dan website itu sendiri merupakan website halaman-halaman yang berisi informasi yang ditampilkan oleh browser seperti Mozila Firefox, Google Chrome atau yang lainnya.” ( Rohi Adulloh,2016)

Xampp adalah perangkat lunak lunak bebas yang bersifat open source pada web server yang yang terdiri dari beberapa database mysql dan bentuk penulisan scriptnya dalam bentuk bahasa pemograman PHP danperl (Mattoet al, 2016)

Diterima Redaksi : 04-04-2020 | Selesai Revisi : 23-04-2020| Diterbitkan Online : 30-04-2020 
Artikel hendaknya memuat tulisan yang berisi 1. Pendahuluan, 2. Metode Penelitian (bisa meliputi analisis, arsitektur, metode yang dipakai untuk menyelesaikan masalah, implementasi), 3. Hasil dan Pembahasan, 4. Kesimpulan, 5. Ucapan terimakasih (kalau ada) dan Daftar Rujukan.

Isi dari pendahuluan adalah jawaban atas pertanyaan (1). Latar belakang, (2). Tinjauan literatur singkat (3). Alasan diadakan penelitian ini dan (4). Pertanyaan tujuan.

\section{Metode Penelitian}

Kerangka penelitian ialah konsep atau urutan kegiatan yang akan dilakukan dalam suatu penelitian. Agar langkahlangkah yang diambil penulis dalam perancangan ini tidak melenceng dari pokok pembicaraan dan lebih mudah dipahami. Urutan langkah-langkah yang akan dibuat penelitian pada gambar 1 .

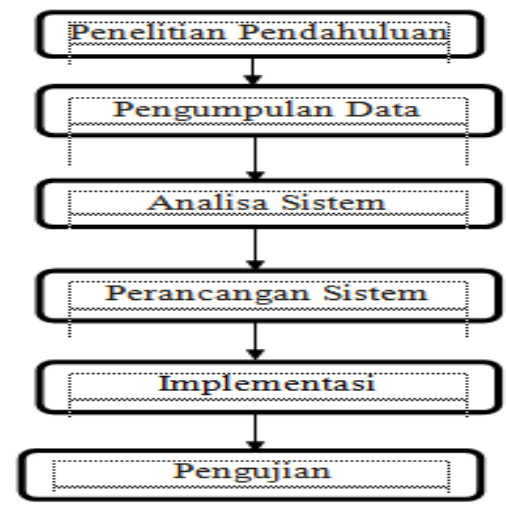

Gambar 1. Kerangka Kerja Penelitian

\subsection{Penelitian Pendahuluan}

Penelitian pendahuluan merupakan langkah pertama dalam melakukan suatu penelitian dengan cara menganalisa terlebih dahulu masalah-masalah yang akan dikembangkan. Dengan tujuan setelah diterapkan aplikasi yang akan dikembangkan ini dapat membantu pengguna (user) dalam juga dapat memberikan informasi kepada pengguna.

\subsection{Pengumpulan Data}

Dalam pelaksanaan penelitian ini dilakukan pengumpulan data dengan cara mewawancarai pemilik CV.Jogja Konveksi secara langsung. Untuk mendapatkan data atau informasi yang pasti.

\subsection{Analisa}

Di dalam proses analisa, terdapat dua tahapan yang harus dilakukan. Adapun dua tahapan tersebut antara lain (1) Analisa Data yaitu data yang diperoleh langsung dari Pemilik CV.Jogja Konveksi, (2) Analisa Proses yaitu metode yang digunakan dalam penelitian adalah dengan menganalisa proses sistem pada CV.Jogja Koveksi agar bisa menyelesaikan masalah yang ada, (3) Analisa Sistem yaitu analisis sistem merupakan dasar dalam merencanakan dan merancang sistem yang akan diterapkan. Analisa sistem dilakukan untuk mengetahui dan mengembangkan sistem yang sedang berjalan. Sistem ini memerlukan beberapa data yang harus dicantumkan dalam aplikasi

\subsection{Perancangan}

Perancangan yang dilakukan dengan menggunakan UML (Unified Modelling language) sebagai tools dalam menjelaskan alur analisa yang akan dibuat dalam melakukan penelitian. UML (Unified Modelling language) yang akan digunakan sebagai berikut: Use Case Diagram, Class Diagram, Sequence Diagram, Activity Diagram.

\subsection{Implementasi Sistem}

Aplikasi sistem informasi penjualan dan distribusi yang dirancang diimplementasikan dengan menggunakan bahasa pemrograman PHP dan Database MySQL sebagai alat bantu dalam melakukan proses konsultasi dan pengolahan datadata tentang penjualan dan penditribusian barang pada CV.Jogja Konveksi. 


\subsection{Pengujian Sistem}

Setelah proses pengumpulan data selesai, maka akan dilakukan proses pengujian terhadap aplikasi yang dibuat dengan menggunakan LAN (Local Area Network) dan juga secara online. Hal ini dilakukan untuk mengetahui apakah program tersebut sudah berjalan sesuai dengan perancangan yang dilakukan (1) LAN (Local Area Network) pada pengujian secara lokal, peneliti akan memanfaatkan sistem jaringan LAN (Local Area Network). Pada pengujian ini peneliti akan menggunakan dua buah komputer, yaitu sebagai client dan server, untuk melihat apakah website yang dijalankan di server bisa juga diakses melalui client, (2) Online yaitu pada pengujian ini peneliti akan meng-hosting atau mendaftarkan website yang telah dibangun ke internet agar website bisa diakses secara online melalui web browser. Dalam hal ini peneliti akan menghosting website ke hostinger yang masih belum berbayar, (3) Pengujian Aplikasi dapat dinyatakan sebagai proses validasi dan verifiksi bahwa aplikasi tersebut dapat memenuhi kebutuhan yang mendasari perancangan alplikasi tersebut dan berjalan sesuai dengan yang diharapkan, (4) Pengujian Interface terhadap model interface yang dilakukan dengan pengamatan secara langsung oleh pengguna interaksi secara langsung dengan model interface yang disajikan dalam bentuk prototype. Ini dilakukan agar kesalahan dapat terdekteksi dan di rubah secara cepat.

\subsection{Analisa Sistem}

Unifed Modeling Language (UML) merupakan suatu alat bantu dengan standarisasi bahasa pemodelan untuk membangun perangkat lunak yang dibangun dengan menggunakan teknik pemrograman berorientasi objek. UML muncul karena adanya kebutuhan pemodelan visual untuk menspesifikasikan, menggambarkan, membangun dan dokumentasi dari sistem perangkat lunak. Pemodelan UML menggunakan diagram dan teks-teks pendukung.

\section{Use Case Diagram}

Use Case Diagram berfungsi untuk menggambarkan kebutuhan fungsional dan menggambarkan kelakuan (behavior) sistem yang akan dibuat serta mendeskripsikan sebuah interaksi antara satu atau lebih aktor dengan sistem yang akan dibuat. Use Case Diagram pada sistem penjualan CV. Jogja Konveksi pada gambar 2.

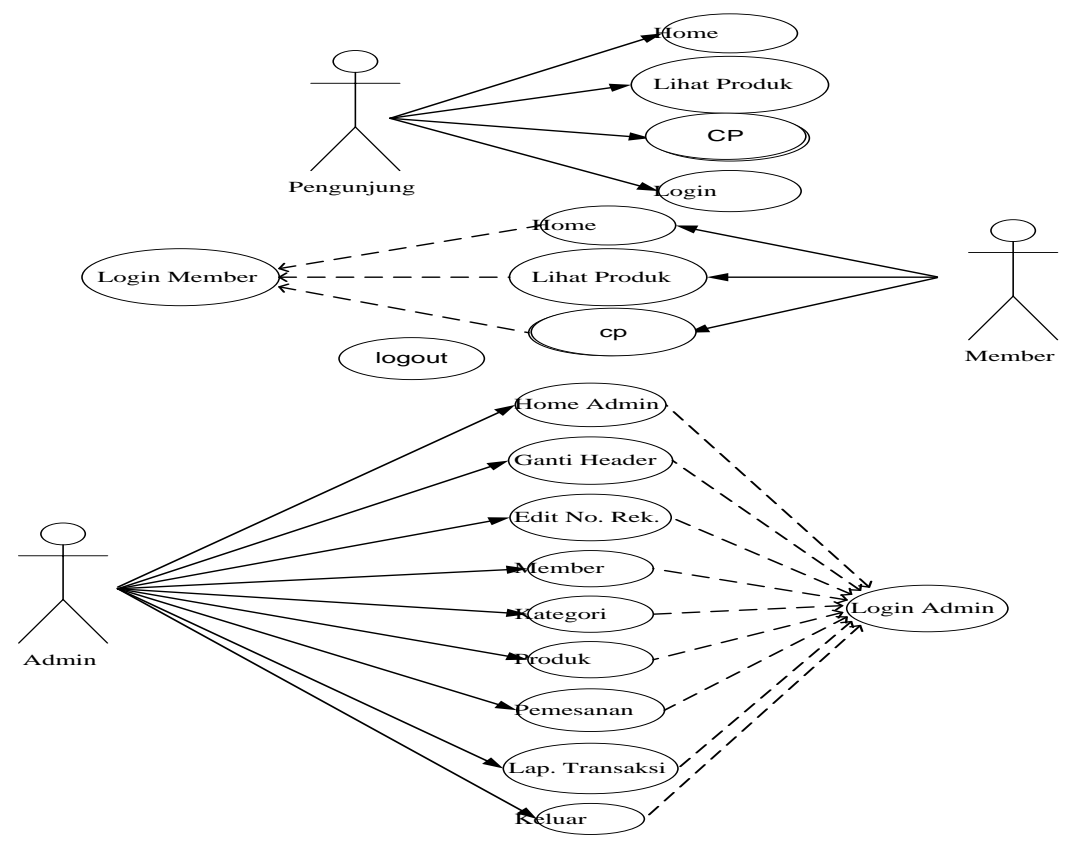

Class Diagram

Gambar 2 Use Case Diagram penjualan

Class Diagram menggambarkan hubungan antara tabel-tabel yang ada dalam database. AdapunClass Diagram pada penjualan produk online CV. Jogja Konveksi pada gambar 3. 


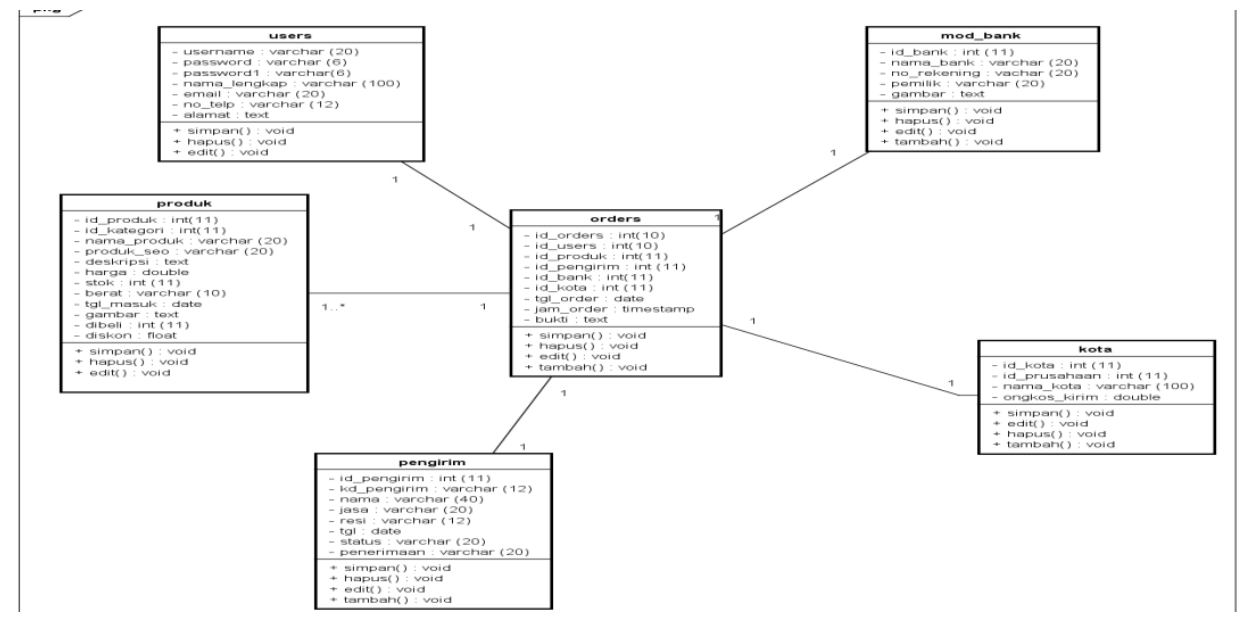

Gambar 3 Class Diagram Penjualan Produk Online CV. Jogja Konveksi

\section{Activity Diagram}

Activity Diagram menggambarkan berbagai alir aktivitas dalam sistem yang sedang dirancang, bagaimana masingmasing alir berawal, decisionyang mungkin terjadi, dan bagaimana mereka berakhir. Activity Diagram pada sistem ini dapat dijelaskan (1) Activity Diagram Pengunjung adalah Activity Diagram pada pengunjung menggambarkan aliran aktivitas atau aliran kerja yang dapat dilakukan oleh pengunjung di dalam sistem penjualan berbasis web ini. Model activity diagram pada pengunjug tersebut pada gambar 4.

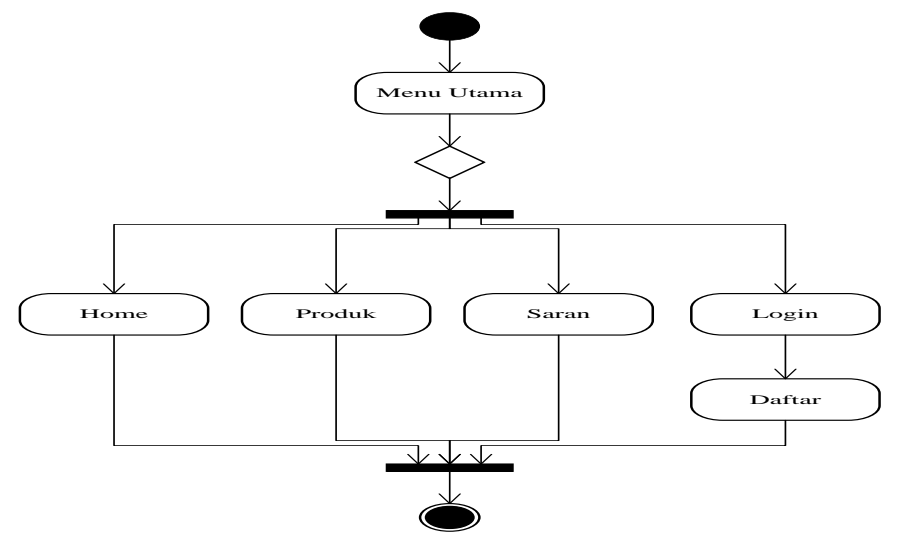

Gambar 4 . Activity Diagram Pengunjung

\section{Hasil dan Pembahasan}

\section{Halaman Utama}

Tampilan Utama pengunjung berguna untuk melihat produk tanpa menjadi member terlebih dahulu. Dengan tampilan pada gabar 5 . 


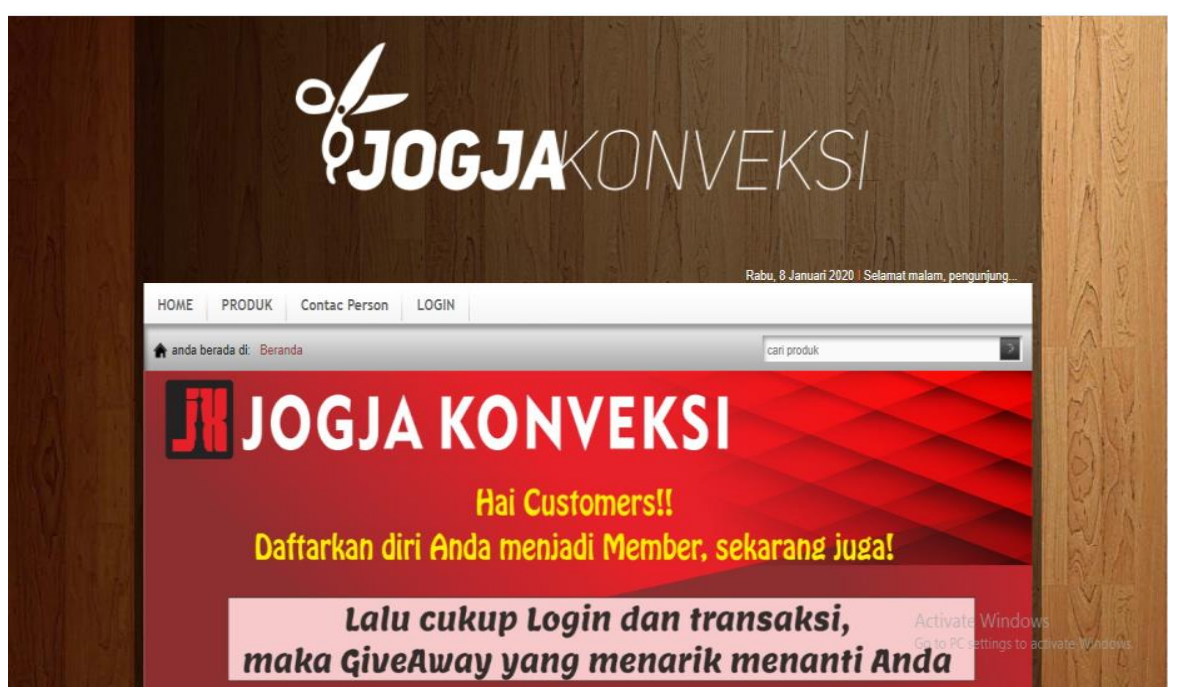

Gambar 5 Tampilan Utama Pengunjung

Halaman Produk

Tampilan Halaman Produk berguna untuk melihat produk yang ada pada website. Dengan tampilan pada gambar 6.
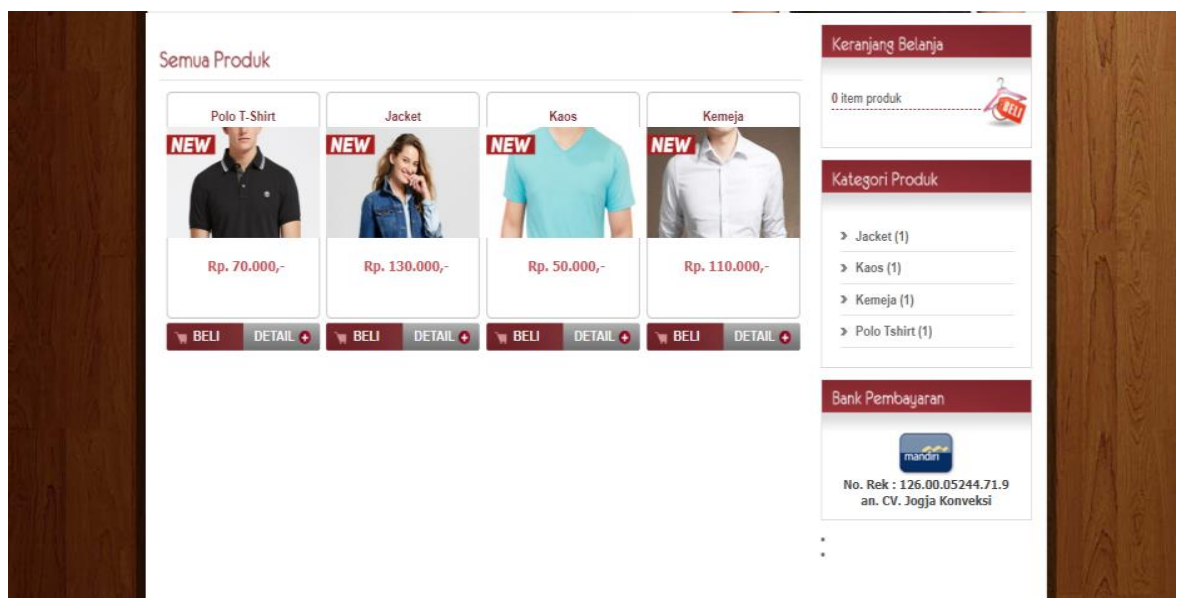

Gambar 6 Tampilan Halaman Produk

Halaman Contac Person

Tampilan Halaman Contac Person berguna untuk memberikan saran atau menghubungi kepada pemilik website. Dengan tampilan pada gambar 7.

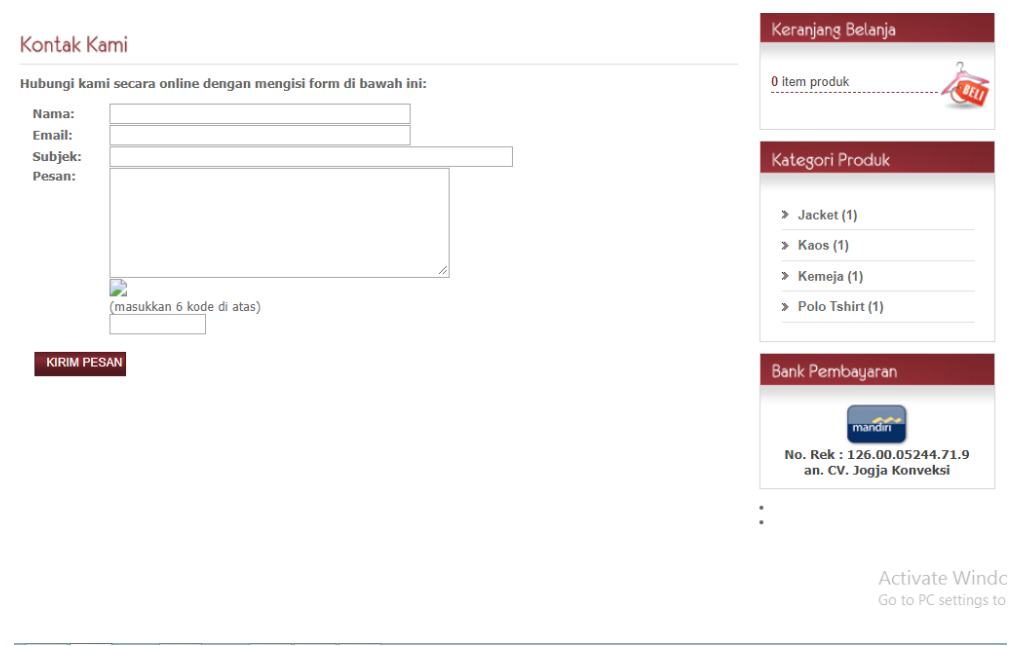

Gambar 4.3 Tampilan Halaman Saran

Jurnal Teknologi Vol 10 NO 1 (20xx ) 1-7 


\section{Halaman Registrasi}

Tampilan Halaman Registrasi atau Daftar berguna untuk mendaftar sebagai member. Dengan tampilan pada gambar 8.

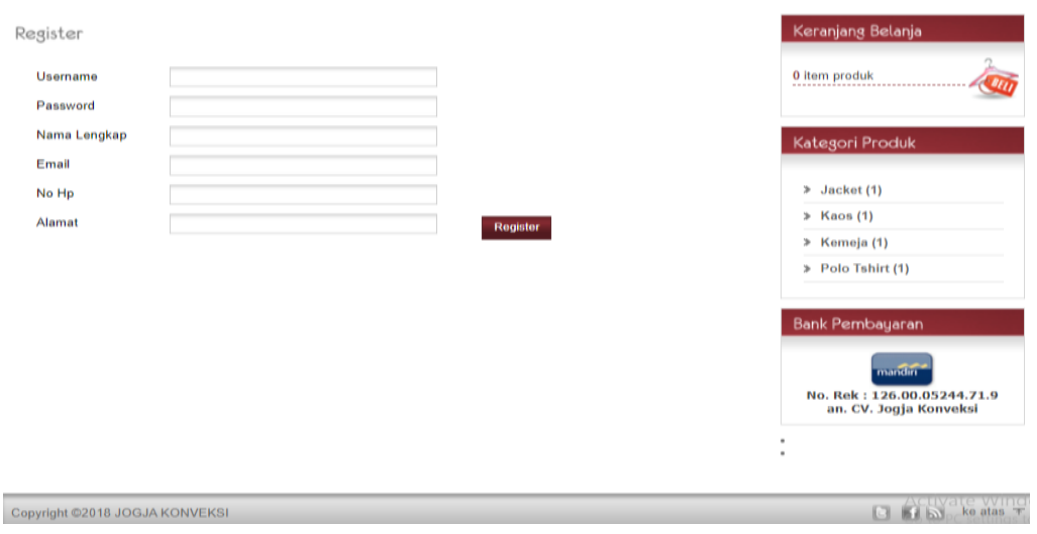

Gambar 8 Tampilan Halaman Registrasi

\section{Cetak Faktur}

Tampilan Halaman Cetak Faktur berguna untuk menampilkan daftar produk yang sudah dibeli dengan total biaya pengiriman. Dengan tampilan pada gambar 9.

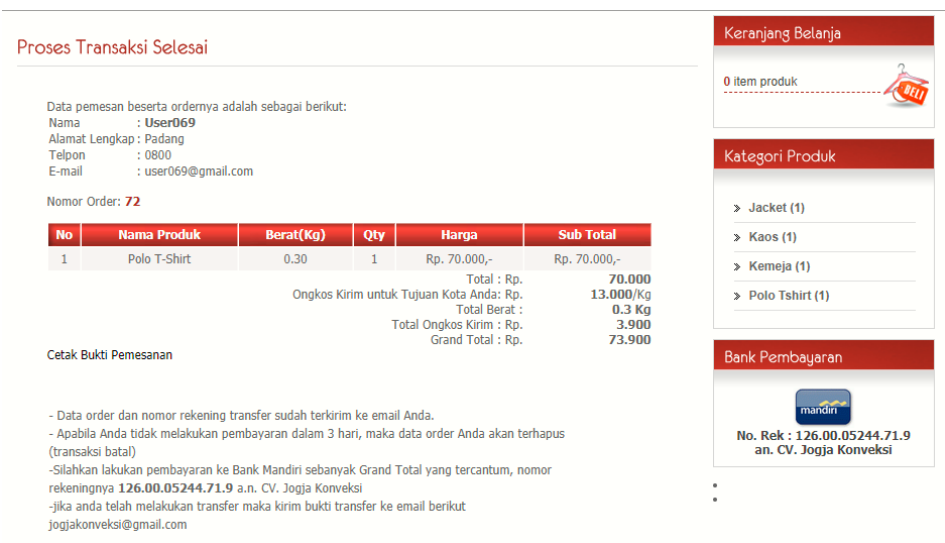

Gambar 9 Tampilan Halaman Cetak Faktur

\section{Laporan Data Transaksi}

Tampilan Laporan Data Transaksi merupakan laporan tentang data transaksi yang telah dilakukan. Dengan tampilan pada gambar 10.

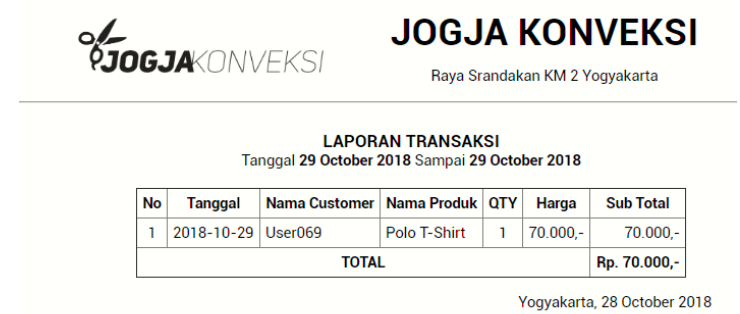


Triyolla Ivadina, Yuhandri , Aggy Paramana Gusman Jurnal Teknologi Vol 10 No 1 (2020) 1-7

\subsection{Bullet dan Numbering}

Pada dasarnya disarankan untuk tidak menggunakan numbering (1,2,3..,a,b,c dst) dalam pembahasan naskahnya, ubah menjadi dalam bentuk kalimat. Hindari menggunakan Bullet/daftar berurut dengan simbol *, $\sqrt{ }$ dan lainnya.

\section{Kesimpulan}

Dengan adanya rancangan sistem yang baru dapat memudahkan konsumen dalam proses transaksi yang dilakukan. Karena dengan pemanfaatan media internet, proses transaksi yang awalnya masih dilakukan secara manual sekarang dapat dilakukan secara online. Hal tersebut mempermudah pelanggan melakukan transaksi dimana saja tanpa harus datang ke Toko CV. Jogja Konveksi serta dengan adanya Sistem Informasi Berbasis Web ini, konsumen dapat melihat berbagai informasi langsung melalui web yang telah dirancang dimana saja dan kapan saja dan adanya sistem yang baru akan dapat menunjang operasional pemasaran toko

\section{Daftar Rujukan}

[1] Abdulloh, Rohi. 2016. Easy dan Simple Web Programming. Jakarta: Elex Media Komputindo.

[2] AS, Rosa dan Shalahudin, M. 2015. RekayasaPerangkatLunak. Bandung: Informatika Bandung.

[3] Burange A. W \& Misalkar H. D, Review of Internet of Things in Development of Smart Cities with Data Management \& Privacy.: IEEE, 2015

[4] Djahir, Y dan Pratita, D. 2015. Bahan Ajar Sistem Informasi Manajemen. Yogyakarta: Budi Utama

[5] Dwi Puspita dan Siska Irianti.2015.Perancangan Sistem Informasi Pemesanan Dan Pembayaran Pada Percetakan Mahardika.Indonesia Jurnal, vol 2: hal 2

[6] Hartiwi., Yessi. (2017). Analisis Dan Implementasi Sistem Informasi Penjualan Berbasis Web Pada Scarlet Butik. JURNAL ILMIAH MEDIA SISFO, 11.1: 752-766

[7] Iswandy, Eka. 2015. Sistem Penunjang Keputusan Untuk Penerimaan Dana Santunan Sosial Anak Nagari Dan Penyaluran Bagi Mahasis wa Dan Pelajar Kurang Mampu Di Kenagarian Barung-Barung Balantai Timur.Jurnal Teknoif, 2, 2338-2724

[8] J. Hutahaean, Konsep Sistem Informasi, Yogyakarta: Deepublish, 2015.

[9] Junaidi, A. (2015). Internet of Things, Sejarah, Teknologi dan Penerapannya. Jurnal Ilmiah Teknologi Informasi Terapan, 1(3).

[10] Kumar S \& Tschofenig H Keoh S. L, "Securing the Internet of Things A Standardization Perspective," IEEE Internet of Things Journal, 2014

[11] Krismiaji. 2015. Jurnal Sistem Informasi Akuntansi. Yogyakarta: Sekolah Tinggi Ilmu Manajemen YKPN.

[12] MADCOMS. 2016. Sukses Membangun Toko Online dengan PHP \& MySQL.Yogyakarta: C.V Andi Offset.

[13] Mulyadi. (2016). Sistem Informasi Akuntansi. Jakarta: Salemba Empat

[14]Pibriana, D., \& Ricoida, D. I. (2017). Analisis Pengaruh Penggunaan Internet Terhadap Minat Belajar Mahasiswa (Studi Kasus: Perguruan Tinggi di Kota Palembang). JATISI (Jurnal Teknik Informatika dan Sistem Informasi), 3(2), 104-115

[15]Ricoida, D.I dan Pibriana,D. (2017). Analisis Pengaruh Penggunaan Internet Terhadap Minat Belajar Mahasiswa (Studi Kasus:Perguruan Tinggi di Kota Palembang). Jatisi. 3 (2).

[16]Romney, Marshall B dan Paul John Steinbart. 2015. Jurnal Sistem Informasi Akuntansi. Jakarta : Salemba Empat. 